\title{
Identifying the location of fire refuges in wet forest ecosystems
}

\author{
Laurence E. Berry, ${ }^{1,2,5}$ Don A. Driscoll, ${ }^{1,2}$ John A. Stein, ${ }^{1}$ Wade Blanchard, ${ }^{1}$ Sam C. Banks, ${ }^{1}$ \\ Ross A. Bradstock, ${ }^{3}$ And David B. Lindenmayer ${ }^{1,2,4}$ \\ ${ }^{1}$ Fenner School of Environment and Society, The Australian National University, Canberra, \\ Australian Capital Territory 0200 Australia \\ ${ }^{2}$ ARC Centre of Excellence for Environmental Decisions, The NERP Environmental Decisions Hub, \\ Fenner School of Environment and Society, The Australian National University, Canberra, \\ Australian Capital Territory 0200 Australia \\ ${ }^{3}$ Centre for Environmental Risk Management of Bushfires, School of Biological Science, University of Wollongong, Wollongong, \\ New South Wales 2522 Australia \\ ${ }^{4}$ Long Term Ecological Research Network, Terrestrial Ecosystem Research Network, Fenner School of Environment and Society, \\ The Australian National University, Canberra, Australian Capital Territory 0200 Australia
}

Abstract. The increasing frequency of large, high-severity fires threatens the survival of old-growth specialist fauna in fire-prone forests. Within topographically diverse montane forests, areas that experience less severe or fewer fires compared with those prevailing in the landscape may present unique resource opportunities enabling old-growth specialist fauna to survive. Statistical landscape models that identify the extent and distribution of potential fire refuges may assist land managers to incorporate these areas into relevant biodiversity conservation strategies.

We used a case study in an Australian wet montane forest to establish how predictive fire simulation models can be interpreted as management tools to identify potential fire refuges. We examined the relationship between the probability of fire refuge occurrence as predicted by an existing fire refuge model and fire severity experienced during a large wildfire. We also examined the extent to which local fire severity was influenced by fire severity in the surrounding landscape. We used a combination of statistical approaches, including generalized linear modeling, variogram analysis, and receiver operating characteristics and area under the curve analysis (ROC AUC).

We found that the amount of unburned habitat and the factors influencing the retention and location of fire refuges varied with fire conditions. Under extreme fire conditions, the distribution of fire refuges was limited to only extremely sheltered, fire-resistant regions of the landscape. During extreme fire conditions, fire severity patterns were largely determined by stochastic factors that could not be predicted by the model. When fire conditions were moderate, physical landscape properties appeared to mediate fire severity distribution.

Our study demonstrates that land managers can employ predictive landscape fire models to identify the broader climatic and spatial domain within which fire refuges are likely to be present. It is essential that within these envelopes, forest is protected from logging, roads, and other developments so that the ecological processes related to the establishment and subsequent use of fire refuges are maintained.

Key words: disturbance ecology; fire refuges; forest management; habitat fragmentation; high-severity fires; landscape modeling; model validation; topography; Victorian Central Highlands, Australia; wet montane forest.

\section{INTRODUCTION}

Landscape-scale high-severity fire can alter ecosystem structure and extent across large areas (Bradstock et al. 2005, Bowman et al. 2009). The increasing frequency of these events is predicted to continue with climate change (McKenzie et al. 2004). This presents a challenge to faunal conservation in fire-prone ecosystems, as species' survival becomes dependent on the limited distribution

Manuscript received 4 September 2014; revised 24 December 2014; accepted 17 February 2015; final version received 20 March 2015. Corresponding Editor: T. G. O'Brien.

${ }^{5}$ E-mail: laurence.berry@anu.edu.au of suitable habitat in fire-modified landscapes (Driscoll et al. 2010). However, within the extent of large fires, local variation in fire severity may preserve critical resources for fauna that depend on unburned habitat for foraging and denning (Mackey et al. 2002). These fire refuges may facilitate species survival in-situ following extensive wildfires (Whelan 1995, Mackey et al. 2002, Robinson et al. 2013).

Intact habitat patches within the boundaries of large fires may provide essential resources to facilitate species survival until the surrounding landscape can be successfully recolonized (Stuart-Smith et al. 2002, Bradstock et al. 2005, Cook and Holt 2006, Castro et al. 2010). The importance of refuges in facilitating survival will vary 
between species and is dependent on whether refuges provide critical resources that are absent from the surrounding landscape (Robinson et al. 2013). Fire refuges may be especially important for fauna that are dependent on mature vegetation features, such as tree hollows for nesting or denning (Banks et al. 2011b). The likelihood of a location acting as a refuge will depend on individual species characteristics, such as competitive behavior and dispersal ability (Brown et al. 2013). Fire refuges may ensure that ecosystem functions provided by species remain in the landscape (Nugent et al. 2014). These functions may remain absent for successive generations if recolonization occurs gradually from exsitu areas (Banks et al. 2011a).

The occurrence of unburned refuges may depend on two sets of processes. Refuge establishment may occur as a result of stochastic fire behaviors unique to individual events (Robinson et al. 2013). Alternatively, refuge formation may be attributable to deterministic processes influenced by physical variation in the landscape (Lindenmayer et al. 1999, Bradstock et al. 2010, Robinson et al. 2013). Both stochastic and deterministic refuges may enable the short-term persistence of fauna by sheltering individuals from the immediate effects of fire (Leonard et al. 2014). Deterministic refuges may enable the survival of species sensitive to short fire return intervals (Robinson et al. 2014). Such areas enable important biological legacies to remain in the landscape (Franklin et al. 2000).

Deterministic fire refuges can form in response to topographic characteristics, such as elevation and aspect, and fire-vegetation interactions, such as vegetation type, stand age, and fire return interval (Mackey et al. 2002). In fire-prone ecosystems, interactions between fire and topography can be a dominant driver of the distribution and extent of different vegetation communities (Wood et al. 2011). For example, within topographically diverse montane forest landscapes, firesensitive vegetation communities are generally restricted to sheltered gullies and areas of lower elevation (Lindenmayer et al. 2009b). However, under extreme fire conditions, the physical and topographic attributes of the landscape may exert less of an influence on fire severity patterns as a wider range of fuels become available to fires (Turner and Romme 1994).

Under extreme fire conditions, the distribution of potential fire refuges may be limited to only the most sheltered parts of the landscape (Mackey et al. 2002). Following a large fire in Victoria (southeast Australia), only $\sim 1 \%$ of the total area within the fire boundary presented unburned refuge areas $>1$ ha in size (Leonard et al. 2014). The conservation of rare, old-growth dependent species in fire-prone montane forests may be dependent on the retention of larger areas of intact, unburned habitat (Lindenmayer et al. 2013). Therefore, it is essential that land managers are able to predict the occurrence of potential fire refuges in order to incorpo- rate them into relevant biodiversity management strategies.

Contemporary fire management planning rarely includes consideration of the mechanisms, such as fire refuges, that may allow species to persist in landscapes following large-scale wildfires (Clarke 2008). The primary objective of most fire management efforts in montane forests is to preserve property and infrastructure (DSE 2012). Intense land-use practices, such as industrial clear-fell logging, can compound the negative effects of fire on biodiversity (Lindenmayer et al. 2011). However, management practices that encourage connectivity between habitat patches within production forests may have positive biodiversity outcomes (Lindenmayer 1994). The inclusion of fire refuges in land management planning may greatly increase biodiversity retention following landscape-scale fires (Robinson et al. 2013). Statistical landscape models that predict the occurrence of potential fire refuges may help land managers to identify and protect areas of the landscape of high conservation value (Mackey et al. 2012).

A small number of studies have used models in an attempt to predict the potential distribution of fire refuges (Camp et al. 1997, Mackey et al. 2002, Wood et al. 2011). These models are developed from a number of landscapelevel variables, such as vegetation type, climatic conditions, fuel loads, soil wetness, and topography (Gill et al. 1987). However, these predictive models are often based upon a suite of theoretical assumptions. These include setting fire weather conditions as constant (Bradstock et al. 2010) and overlooking the influence of land-use practices on fire behavior at the landscape scale (Taylor et al. 2014a). Models predicting the outcome of large wildfires are rarely evaluated using data collected following actual fire events.

We compared the outcomes of a predictive fire model with fire severity data collected following a large wildfire. Mackey et al. (2002) developed a predictive model of fire refuges in the forests of the Victorian Central Highlands, Australia. In February 2009, the Kilmore East-Murrindindi fire complex burned $\sim 250000$ ha of this region (Leonard et al. 2014, Robinson et al. 2014), providing a unique opportunity to test the earlier predictions about fire refuges. We asked two questions: (1) How do areas in the landscape predicted to act as fire refuges mediate the severity of large fires? (2) How does the predicted distribution of fire refuges vary under different fire conditions? We expected to identify a positive relationship between the modeled probability of refuge occurrence and the scale and the presence of low-severity fire. We also expected regions of high-severity crown fire to be correlated with a lower probability of refuge occurrence.

\section{Methods}

Study area, fire conditions, and fire severity data

Mackey et al. (2002) modeled the probability of fire refuge occurrence in the Maroondah and O'Shannassy 


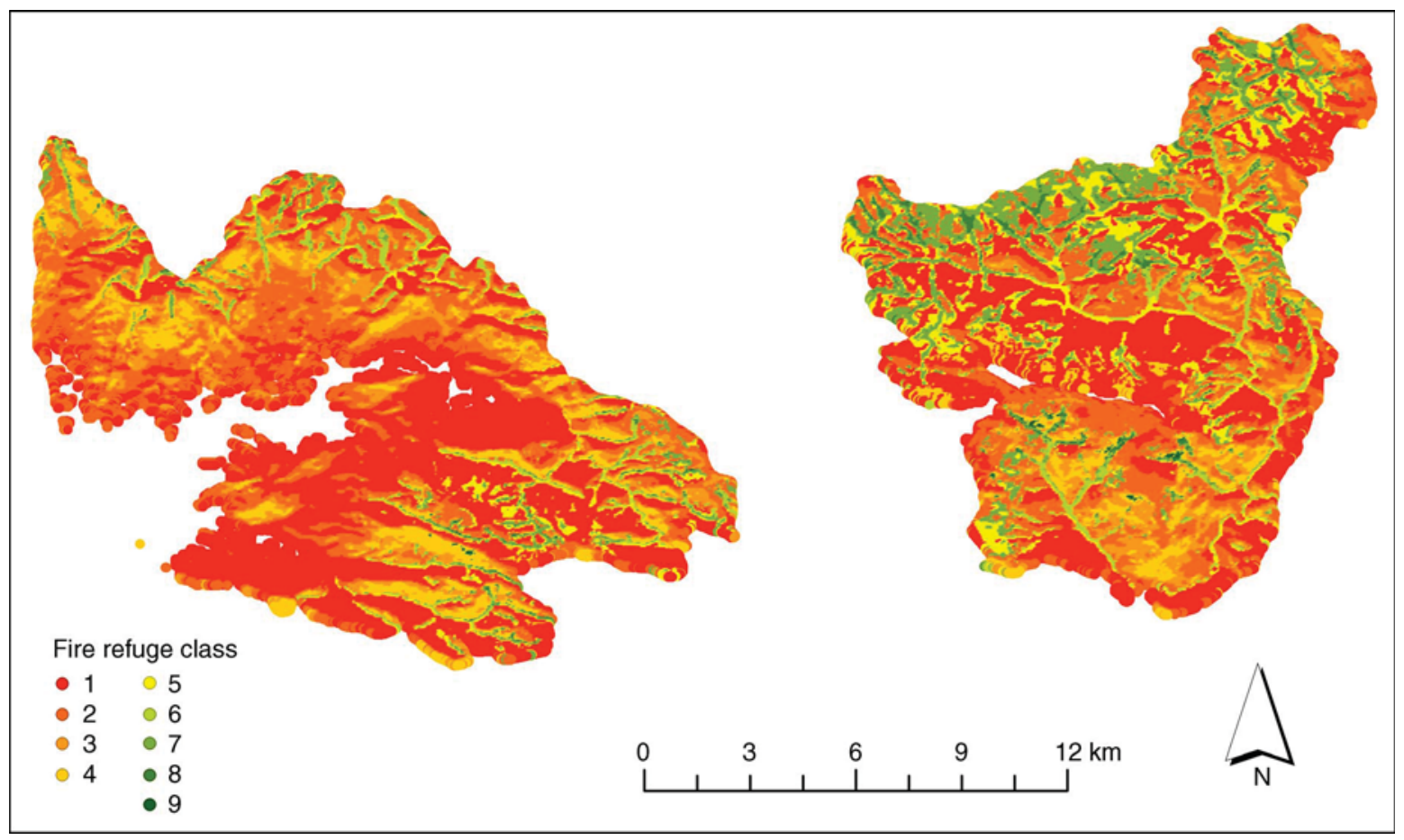

FIG. 1. Map displaying the probability of fire refuge occurrence in the Maroondah (left) and O'Shannassy (right) catchments of the Victorian Central Highlands, northeast of Melbourne, Australia. The figure has been adapted from Mackey et al. (2002). See Table 1 for an explanation of the predicted refuge class scale.

water catchments located in the Victorian Central Highlands ( $\mathrm{VCH})$, northeast of Melbourne, Australia (see Appendix A). This region was chosen as it contains strong environmental gradients and topographically variable areas of high relief upon which to calculate model projections. We limited our analyses of the Mackey et al. (2002) model to areas within the boundaries of O'Shannassy and Maroondah water catchments. Within each catchment, only areas within the extent of the 2009 fire boundary were analyzed (Fig. 1). This allowed the potentially confounding effects of logging and other land uses to be minimized, because the catchments are largely unlogged and uncleared.

The 2009 Black Saturday fires occurred following a period of protracted drought (Teague et al. 2010). Wind speeds during these fires reached $57 \mathrm{~km} / \mathrm{h}$ (Tolhurst et al. 2010). The interaction between a period of prolonged drought, consecutive days of temperatures exceeding $43^{\circ} \mathrm{C}$, and large stands of predominantly single-aged 1939 regrowth forest (the dominant forest age class in both catchments) created conditions conducive for high intensity crown fires (Teague et al. 2010, Taylor et al. $2014 b$ ). Each catchment was subject to fires burning under different weather conditions as measured by the McArthur Forest Fire Danger Index (FFDI; Noble et al. 1980). The O'Shannassy water catchment was burned during a catastrophic weather period (i.e., FFDI $>100$ ), categorized by rapidly moving, uncontrollable fire (Teague et al. 2010). The Maroondah catchment was burned by a slower moving moderate class fire (i.e., FFDI $<10$ ) during the period following a southerly weather change in the evening of 7 February prior to midnight, which brought strong winds, high humidity, and low temperatures (Price and Bradstock 2012, Engel et al. 2013). This provided an opportunity to test the performance of the Mackey et al. (2002) model under different fire conditions. We tested the Mackey et al. (2002) model using data from fire severity maps produced by the Department of Sustainability and Environment (DSE), Victoria, Australia (Fig. 2). Fire severity maps were produced at a scale of 1:25000 from SPOT satellite imagery using the Normalized Burn Ratio (NBR) index (DSE 2009).

\section{Short summary of the Mackey et al. (2002) modeling approach}

Mackey et al. (2002) combined survey data of vegetation community composition at sites distributed widely across the Maroondah and O'Shannassy water catchments and preexisting GIS layers to generate spatial predictions of potential fire refuge occurrence. These spatial predictions were expressed as a map describing the probability of a location remaining unburned (Fig. 1). Vegetation survey data from longterm research sites in the study region were used to compare the spatial distribution of vegetation types to environmental gradients, such as elevation, slope, and aspect. Mapped GIS data for the O'Shannassy and 


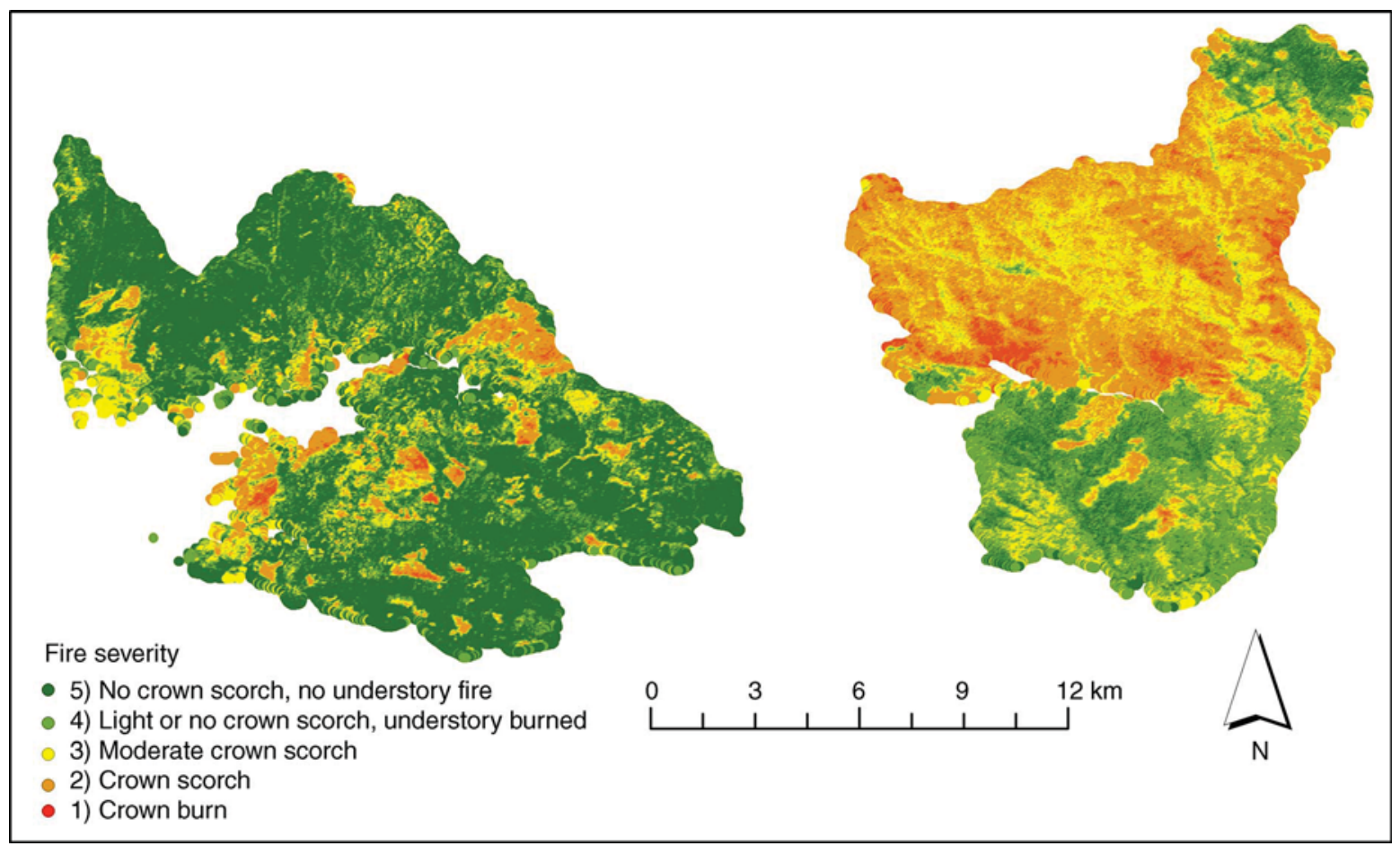

FIG. 2. Fire severity distribution in the Maroondah (left) and O'Shannassy (right) catchments. Data were taken from DSE (2009) SPOT satellite imagery.

Maroondah catchments enabled these comparisons to be projected across the landscape. The presence or absence of different forest types was correlated with a series of spatially explicit environmental gradients using topographic environmental domain analysis (TEDA), a GIS-based data analysis technique. The gradients were mean annual temperature, elevation percentile, shortwave radiation, topographic-wetness index, elevation, aspect, catchment area, elevation difference from mean, and slope. Forest type was classified according to species composition and stand age. The TEDA results provided a model of the probability that a location supports oldgrowth forest. These estimates were converted to estimates of the mean interval between stand-replacing fires (Johnson and Gutsell 1994). The gridded probabilities generated by the multi-agedness model derived from analysis of the site-based data were combined with the longest mean fire interval models produced from the TEDA analyses to predict the probability of a location being a refuge for arboreal marsupials (Mackey et al.
2002). The Mackey et al. (2002) fire refuge probability modeling procedure produced a raster grid of refuge potential with cells attributed values of increasing probability scaled from 1 to 9 , where 1 corresponds to a low probability of the location remaining unburned and 9 corresponds to a high probability of the location remaining unburned (Table 1).

\section{Ground-truthing the remotely sensed DSE fire severity map}

We independently ground-truthed the accuracy of the DSE fire severity maps using field observations of fire severity obtained from fire-affected long-term research sites (Lindenmayer et al. 2014a). This step was necessary to quantify the accuracy of the DSE fire severity mapping. The NBR accurately classifies areas of highseverity fire, which are characterized by substantial changes in canopy structure (Cocke et al. 2005). However, the NBR approach to fire severity mapping may underestimate understory burn severity when the

TABLE 1. An explanation of the topographic and vegetative properties at each end of the predicted refuge class probability scale derived from Mackey et al. (2002).

\begin{tabular}{cc}
\hline \hline $\begin{array}{c}\text { Predicted } \\
\text { refuge class }\end{array}$ & Topographic and vegetative characteristics \\
\hline 1 & $\begin{array}{c}\text { low percentile mean fire interval }(<100 \text { years }) \text {, low probability of multi-agedness }(<25 \%), \text { lower mean } \\
\text { topographic wetness index }(\mathrm{TWI}), \text { higher elevation percentile, higher mean annual temperature } \\
90-100 \% \text { percentile mean fire interval }(>500 \text { years }), \text { high probability of multi-agedness }(>65 \%), \text { higher mean } \\
\text { topographic wetness index }(\mathrm{TWI}), \text { lower elevation percentile, lower mean annual temperature }\end{array}$ \\
&
\end{tabular}


TABLE 2. A summary of range and sill values for variograms using spatially lagged response variables at different scales to account for spatial dependence in two catchments of the Victorian Central Highlands, northeast of Melbourne, Australia.

\begin{tabular}{|c|c|c|c|}
\hline Fire severity, by catchment & SLRV & Range (m) & Sill \\
\hline \multicolumn{4}{|l|}{ O'Shannassy } \\
\hline \multirow[t]{5}{*}{ Crown fire } & None & $>6000$ & 0.3 \\
\hline & Fm4 & 1500 & 0.12 \\
\hline & Fm8 & 1500 & 0.12 \\
\hline & Fm120 & 2500 & 0.18 \\
\hline & Fm 2600 & $>6000$ & 0.25 \\
\hline \multicolumn{4}{|l|}{ O’Shannassy } \\
\hline \multirow[t]{5}{*}{ Low severity } & None & $>6000$ & 0.25 \\
\hline & Fm4 & 1000 & 0.06 \\
\hline & Fm 8 & 1000 & 0.06 \\
\hline & Fm 120 & 2800 & 0.13 \\
\hline & Fm 2600 & $>6000$ & 0.25 \\
\hline \multicolumn{4}{|l|}{ Maroondah } \\
\hline \multirow[t]{5}{*}{ Crown fire } & None & 6000 & 0.085 \\
\hline & Fm4 & 6000 & 0.035 \\
\hline & Fm8 & 6000 & 0.035 \\
\hline & Fm120 & 6000 & 0.085 \\
\hline & $\mathrm{Fm} 2600$ & 6000 & 0.085 \\
\hline \multicolumn{4}{|l|}{ Maroondah } \\
\hline \multirow[t]{5}{*}{ Low severity } & None & 6000 & 0.158 \\
\hline & Fm4 & 6000 & 0.048 \\
\hline & Fm8 & 6000 & 0.05 \\
\hline & Fm 120 & 6000 & 0.158 \\
\hline & $\mathrm{Fm} 2600$ & 6000 & 0.158 \\
\hline
\end{tabular}

Notes: Fm refers to focal mean, where the severity value of a cell is calculated from the mean of the surrounding cells $(4,8$, 120 , or 2600$)$. In the O'Shannassy catchment, 'Focal mean 4 ' and 'Focal mean 8' (fire severity in the neighboring cells, within $20 \mathrm{~m}$ ) effectively accounted for spatial dependence. In the Maroondah catchment, fire severity was independent of local spatial dependence.

above canopy remains intact (Roy et al. 2006). To quantify the extent of misclassification, ground-truthing sites were selected across the study region, to account for site-specific variation in topography, vegetation, and local fire conditions. We calculated the proportion of sites where fire severity was correctly identified by the DSE fire severity maps, and the proportions of sites where the measures were different by one and two categories. To reduce the likelihood of fire severity misclassification influencing the outcomes of our analyses, we pooled DSE severity categories 4 and 5 (understory burn with canopy intact and both understory and canopy intact) for our analyses of low-severity fire (Table 3). For further details of the ground-truthing process see Lindenmayer at al. (2010).

\section{Spatial dependence}

We conducted Moran's I tests for spatial-autocorrelation in the fire severity maps using the spatial autocorrelation tool in ArcGIS 10.1 (ESRI, Redlands, California, USA). To address any spatial dependence in our logistic regression models, we included a spatially lagged response variable (SLRV) as an auto-covariate
(Haining 2003). To determine the appropriate scale of SLRV to use within each catchment, we measured the influence of SLRVs at different scales on the spatial dependence of 2009 fire severity using variogram analysis. The SLRV was calculated as the mean fire severity of the points surrounding each grid cell using the focal mean function in ArcGIS 10.1 (ESRI, Redlands, California, USA). The sill of a variogram is the semi-variance value at which the fitted line plateaus. The variogram range is defined as the distance at which the sill is reached. The range is the greatest distance at which a point can be considered related to its surroundings. Spatial dependence is evident when a clear sill is reached within the range considered in each variogram. We calculated the SLRV at different scales to test the extent to which spatial dependence should be considered. These were the total areas of the surrounding $4,8,120$, and 2600 cells. This allowed us to consider the spatial influence of the surrounding cells at $20 \mathrm{~m}$ (surrounding 4 or 8 cells), $100 \mathrm{~m}$, and $500 \mathrm{~m}$ on the fire severity of each focal cell $\left(20 \mathrm{~m}^{2}\right)$. A $500 \mathrm{~m}$ measure is consistent with the SLRV approach described in Price and Bradstock (2012), who calculated that the mean gully width was $\sim 500 \mathrm{~m}$ across all of the Victorian Central Highlands fire complexes. Moran's I examines global spatial autocorrelation across each data layer. Whereas, our variogram analysis (Table 2) examined autocorrelation using a SLRV at different local levels $(20 \mathrm{~m}, 100 \mathrm{~m}$, and $500 \mathrm{~m})$

\section{Generalized linear models}

The variogram analyses indicated a high level of spatial dependence in fire severity within each catchment at the 20-m scale (Table 2). Therefore, to achieve independence between our sample points, we used a subset of our data points. Based on the results of our variogram analysis, we selected each point at least $40 \mathrm{~m}$

TABLE 3. List of fire severity response variables and spatially lagged response predictor variables used in auto-logistic models.

\begin{tabular}{ll}
\hline \hline \multicolumn{1}{c}{ Variable } & \multicolumn{1}{c}{ Description } \\
\hline DSE fire & 1) Crown burn \\
severity & 2) Crown scorch \\
categories & 3) Moderate crown scorch \\
& 4) Light or no crown scorch, understory \\
burned & 5) No crown scorch, no understory \\
& burn \\
Crown fire & 1 = DSE fire severity classes $1+2$ \\
& $0=$ classes 3-5 \\
Low-severity fire & $1=$ DSE fire severity classes $4+5$ \\
& $0=$ classes 1-3 \\
Spatially lagged & Focal mean (mean fire severity of \\
response variable & surrounding cells) \\
(SLRV) & fm4 = surrounding 4 cells \\
& fm8 $=$ surrounding 8 cells \\
& fm120 = surrounding 120 cells \\
& fm2600 = surrounding 2600 cells \\
\hline
\end{tabular}

Note: Each grid cell used to construct the SLRV measured 20 $\mathrm{m}^{2}$ 
apart. This is a common method for accounting for spatial dependence in ecological data (Haining 2003). We used binomial generalized linear models to determine the relationship between fire severity and refuge probability class. We fitted crown fire and low-severity fire as response variables and predicted refuge class as the predictor variable (Table 3 ). Analyses were conducted in the $\mathrm{R}$ statistical environment ( $\mathrm{R}$ Development Core Team 2012).

Receiver operating characteristics (ROC) and area under the curve (AUC) analysis

To visualize the performance of the predicted probability of fire refuge occurrence as a successful classifier of fire severity (as crown fire and low-severity fire), we constructed receiver operating characteristics (ROC) graphs (Fawcett 2006). ROC was used over simple classification accuracy measures as it enabled the comparison of different classification systems (Hand and Till 2001). ROC is preferred over cross-validation techniques because, for cross-validation to occur, an arbitrary threshold needs to be selected from the qualifying data to determine if a site is occupied or not. We used area under the curve (AUC) analysis to test whether the model will rank a randomly chosen positive instance higher than a randomly chosen negative instance (Fawcett 2006). An AUC value of 1 can be interpreted as a $100 \%$ prediction rate, whereas, an AUC value of 0.5 indicates an equal number of successful and unsuccessful classifications (Worster et al. 2006). AUC has been described as a misleading measure in assessing the performance of predictive distribution models (Lobo et al. 2008). It is therefore necessary to interpret these results in unison with the auto-logistic regression models. Each ROC refuge probability class figure must be interpreted independently, as the analysis ignores goodness of fit, $P$ values, and spatial dependence (Lobo et al. 2008).

We constructed ROC graphs and used the AUC to determine the ability of each refuge probability class to categorize crown and low-severity fire. To do this, we binomially reclassified each refuge class. The class of interest was reclassified as 1 (cases) and all others as 0 (controls). We then calculated the ROC using the package RORC in R development software (Sing et al. 2005). Refuge probability class was fitted as the predictor variable with crown fire and low-severity fire fitted separately as the response variable. This determined the extent to which each refuge probability class accurately classified both crown and low-severity fire. This was repeated for both of the water catchments we targeted for study. Used in unison with the auto logistic models, this approach enabled the identification of individual refuge classes that reliably predicted areas of crown or low-severity fire. The ROC AUC analysis enabled individual refuge classes that were strong predictors of crown and low-severity fire to be identified. We predicted that refuge class 9 (high probability of a location being unburned) would be a strong predictor of low-severity fire and refuge class 1 (low probability of a location being unburned) would be a strong predictor of crown fire. We predicted refuge classes 2 to 8 to be weaker predictors of crown and lowseverity fire.

\section{RESUlts}

Our ground-truthing of the remotely sensed DSE fire severity map data indicated that $81 \%$ of grid cells were accurately classified. Of the sites incorrectly classified, $14 \%$ were by a misclassification distance of one category and $3.6 \%$ by two categories.

\section{Moran's I tests for spatial autocorrelation}

Fire severity across the O'Shannassy water catchment was highly spatially dependent (Moran's index, 0.79; expected index, 0; variance, 0; $z$ score, 1837.08; $P<$ $0.001)$. Probability of fire refuge occurrence, as derived from the Mackey et al. (2002) model, also was highly spatially dependent (Moran's index, 0.7; expected index, $-0 ; z$ score, 1640.84; $P<0.001)$.

\section{Variograms}

The variogram analysis indicated that both focal mean 4 and focal mean 8 (the mean values of the surrounding four and eight cells; each cell was $20 \times 20$ m) SLRVs effectively accounted for spatial dependence in the O'Shannassy catchment (Table 2). The values for the Maroondah catchment indicated a similarity in fire severity values throughout the landscape, which was independent of localized spatial dependence (see Appendix $\mathrm{B}$ for variogram figures).

\section{Generalized linear models}

In the O'Shannassy catchment, probability of crown fire was highest $(\sim 48 \%)$ in refuge class 1 and lowest in refuge class $9(\sim 2 \%$; Fig. 3). There was a nonlinear response to crown fire between refuge classes 2 and 8 (Fig. 3). The highest probability for low-severity fire was found in refuge class $9(\sim 92 \%)$. The lowest probability of low-severity fire was recorded in refuge class 1 $(\sim 10 \%)$. There was a nonlinear response to low-severity fire between refuge classes 2 and 8 (Fig. 3).

In the Maroondah, catchment probability of crown fire was highest $(\sim 9 \%)$ in refuge class 1 and lowest in refuge class $9(\sim 0 \%$; Fig. 3). The low probabilities of crown fire in the Maroondah catchment were related to the relatively low frequency of crown fire experienced. The probability of each refuge class experiencing lowseverity fire was similar across refuge classes $2-9$ in the Maroondah catchment (Fig. 3). Refuge class 1 experienced the lowest probability of low-severity fire $(\sim 80 \%)$. The high probabilities of low severity across all refuge classes in the Maroondah catchment was related to the relatively high frequency of low-severity fire experienced (Fig. 4). 

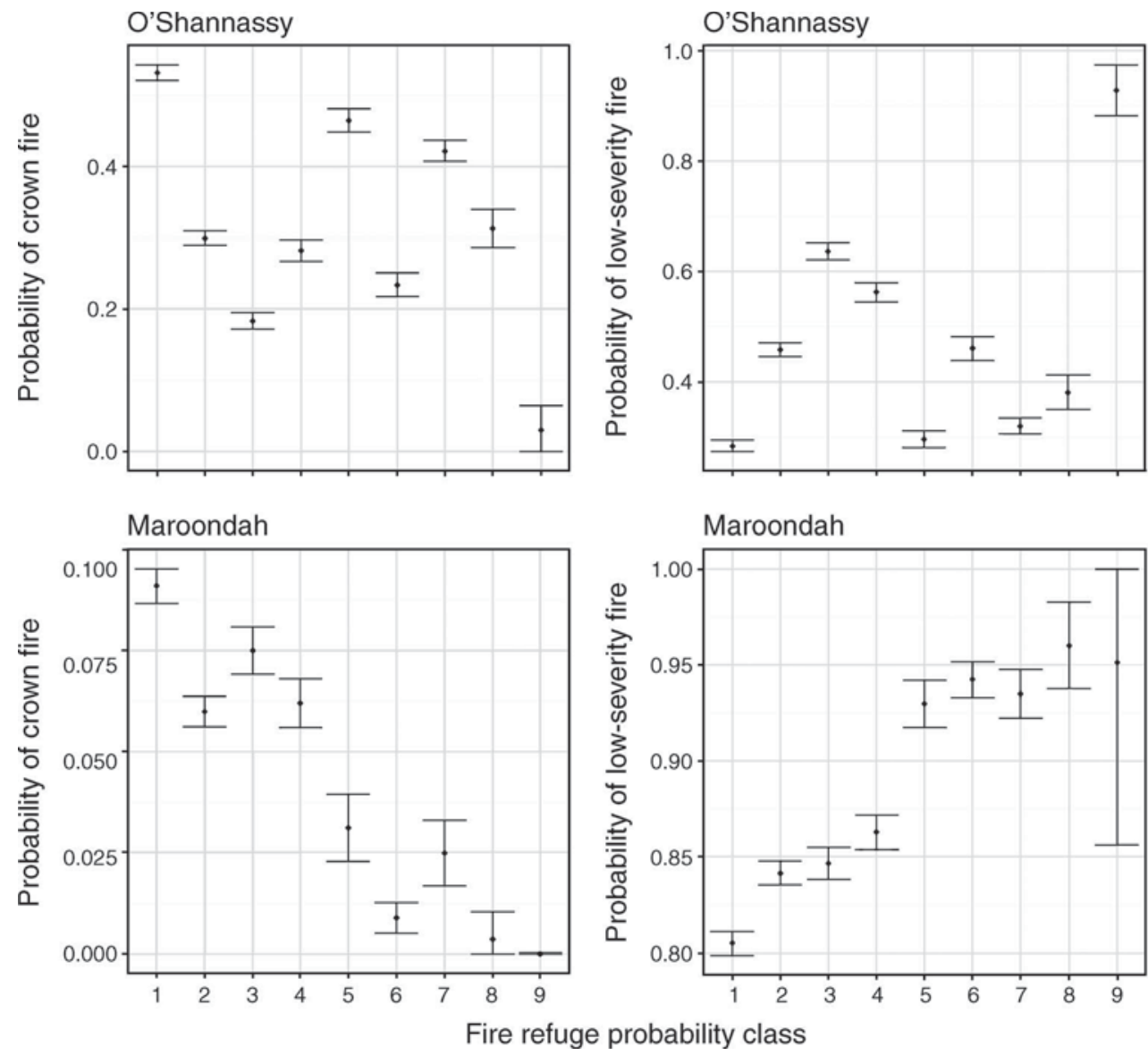

FIG. 3. Probability of crown and low-severity fire occurrence per predicted refuge class in the O'Shannassy and Maroondah water catchments. The $x$-axis indicates refuge probability class as taken from the Mackey et al. (2002) model. Error bars represent $95 \%$ confidence intervals. The $y$-axis scale varies among plots.

\section{ROC AUC}

The ROC AUC analyses for the O'Shannassy catchment indicated that refuge probability class 1 accurately classified crown fire distribution (Fig. 5). Refuge probability class 9 accurately classified the distribution of low-severity fire in the O'Shannassy catchment (Fig. 6). No individual refuge probability class in the Maroondah catchment accurately classified either crown fire or low-severity fire (See Appendix C).

\section{Discussion}

Fire refuges may mitigate the detrimental effects of large fires on fauna habitat, by providing resources unavailable in the surrounding burned landscape (Robinson et al. 2013). Management actions that preserve potential fire refuges are relevant to biodiversity conservation in montane forests globally, as the scale and frequency of natural and anthropogenic disturbances increases (Lindenmayer et al. 2014b). We used a case study to determine how models which predict the distribution of potential fire refuges can be interpreted by land managers to identify fire refuge areas to target for management of biodiversity values in fire prone forests. Our findings indicate that in extreme fire conditions, the presence of fire refuges is limited to extremely sheltered parts of the landscape. The high variability in fire severity in areas with moderate probabilities of being a fire refuge is indicative of the central role played by fire weather in determining postfire outcomes in extreme conditions. It is essential that within potential fire refuge envelopes, detrimental land management practices are minimized and, where possible, areas are protected to enable the ecological processes relevant to the establishment and subsequent use of fire refuges to be maintained (Lindenmayer and McCarthy 2002).

\section{Do predicted fire refuges mediate the severity of large} fires?

Our study found that modeled fire refuges were strong predictors of fire severity. The occurrence of potential fire refuges was limited to areas with an extremely high probability of refuge occurrence (refuge class 9). These fire refuges are characterized by deep, sheltered topography in mesic gullies and late-successional vegetation 

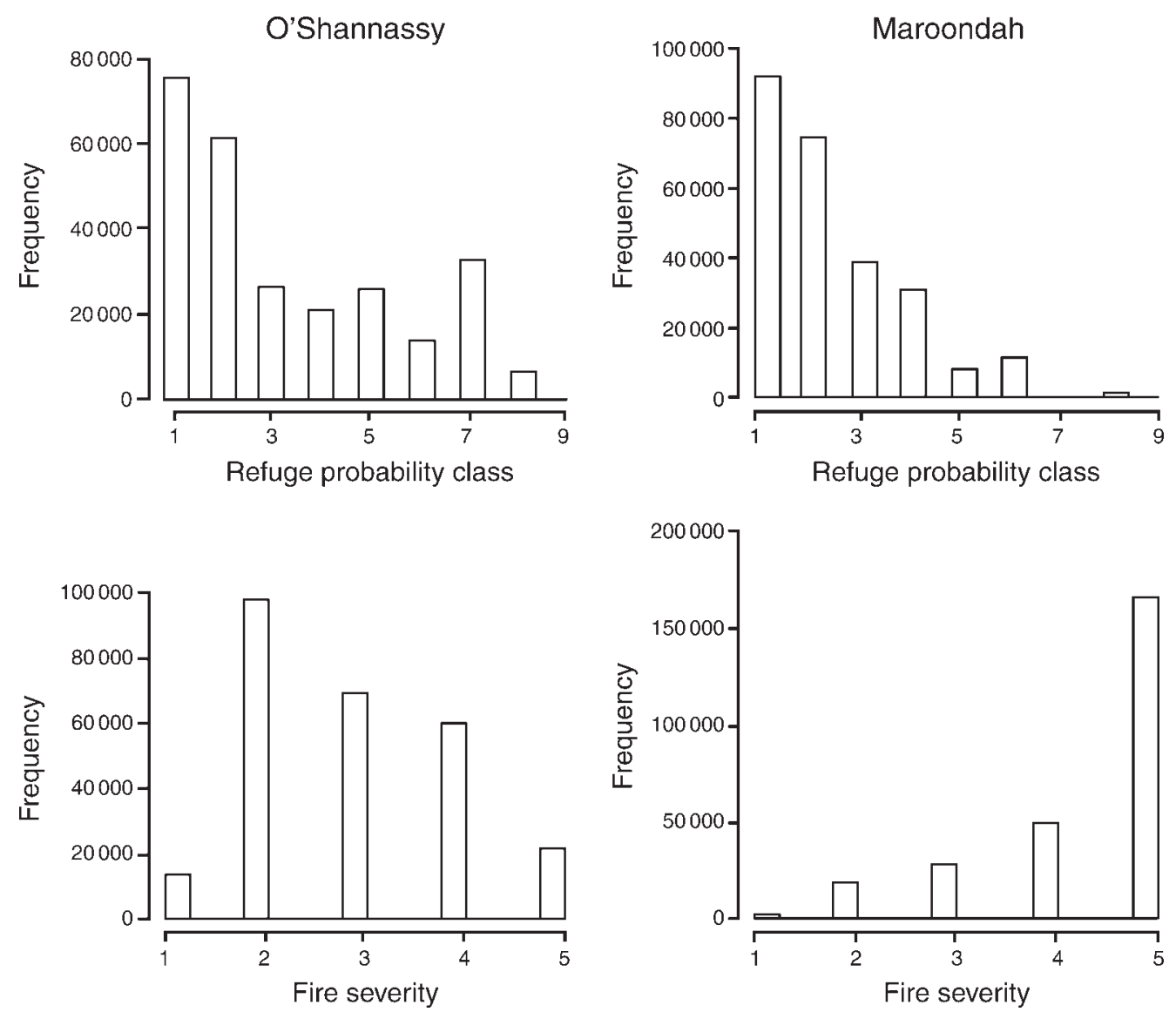

FIG. 4. The frequency of refuge probability grid squares for each class (top) and frequency of each fire severity class (bottom) for each water catchment. Both water catchments were predicted to return high frequencies of potential refuge areas following fire. The observed frequency of fire severity in both catchments indicates that the Maroondah catchment was exposed to predominantly low-severity fire. The inverse was observed in the O'Shannassy catchment. Note that the frequency of extreme high-severity fire in the O'Shannassy catchment was relatively low.

communities (Mackey et al. 2002). These deterministic properties sufficiently moderated fire severity, enabling the persistence of ecologically significant habitat features, such as large hollow-bearing trees (Taylor and Skinner 1998, Lindenmayer et al. 2012b). This is comparable to findings in the boreal forests of Canada and Alaska, where vegetation types of relatively low flammability were associated with areas of low-severity fire (Burton et al. 2008). Our findings suggest that extremes of topography and wetness were the principal contributing factors to fire refuge retention. These regions contribute to the establishment of landscapewide variation in fire severity, which may facilitate species' survival in situ (Robinson et al. 2013, Leonard et al. 2014).

How does the predicted distribution of fire refuges vary under different fire conditions?

Under extreme fire conditions, fire severity was highly variable in all but the most confidently predicted refuge classes. In intermediate refuge classes (2-8), the effects of minor topographic or vegetative variation on exposed slopes had a minimal influence on fire severity. In the subalpine forests of North America, fire intensity and crown fire initiation were strongly related to weather conditions immediately preceding or during the fire (Bessie and Johnson 1995). Areas classified less confidently on the refuge probability scale (refuge classes 2-8) were more likely to be located on more exposed slopes (Mackey et al. 2002). Fire severity in these areas was primarily influenced by weather conditions on the day of the fire than by their physical and topographic properties. It is likely that the highly variable nature of fire weather was responsible for the range of fire severity responses observed across these moderate predicted classes (Bradstock et al. 2010, Price and Bradstock 2012, Sharples et al. 2012).

During moderate fire conditions, fire severity appeared to be topographically mediated, with little evidence of any effects of fire weather. Forest stands that experienced moderate severity or understory burns only may lose foliage but are unlikely to be killed by fire (Chafer et al. 2004). These areas may still present critical resources necessary to the survival of many specialist 

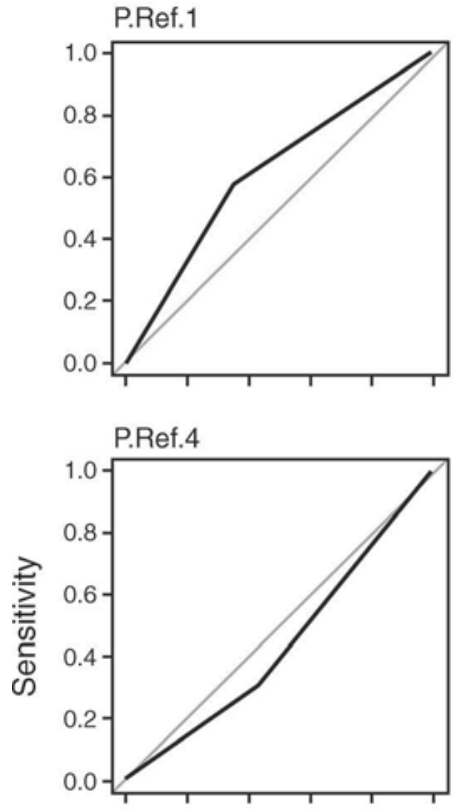

P.Ref.7

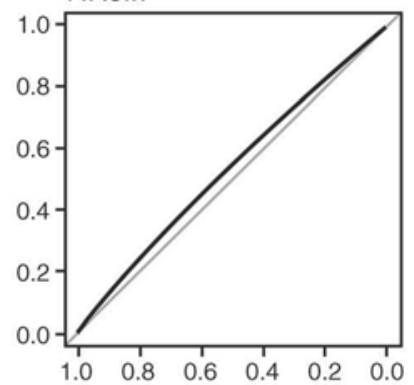

\section{Crown fire}

P.Ref.2

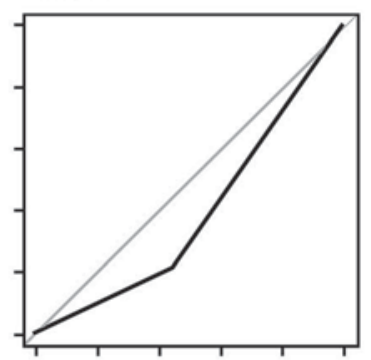

P.Ref.5

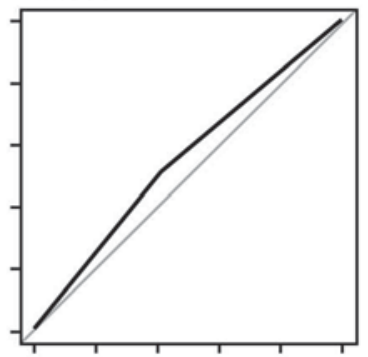

P.Ref.8

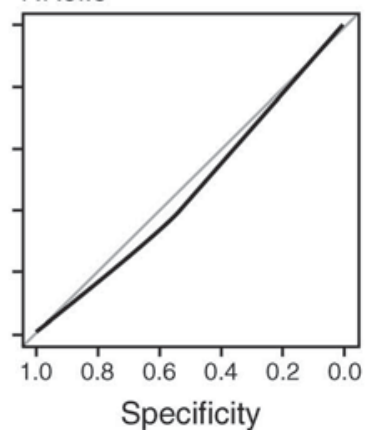

P.Ref.3

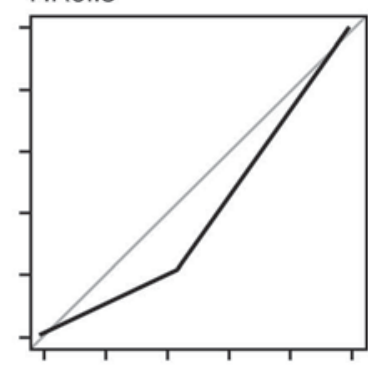

P.Ref.6

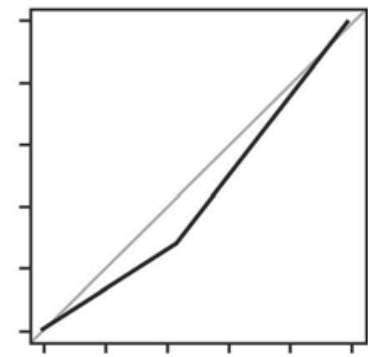

P.Ref.9

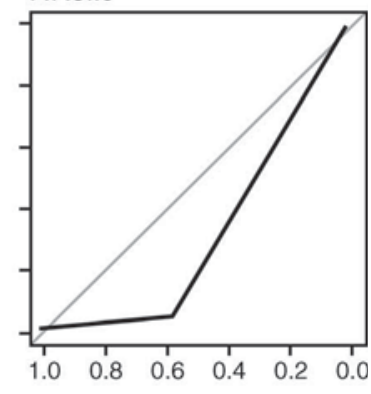

FIG. 5. Receiver operating characteristics (ROC) curves and area under the curve analysis (AUC) displaying crown fire classification accuracy for each refuge probability class in the O'Shannassy catchment. Specificity represents the false positive rate. Sensitivity represents the true positive rate. The gray line indicates a random response and the black line is the performance of each refuge class in accurately predicting crown fire. P.Ref.1-P.Ref.9 is refuge probability class 1-refuge probability class 9 , respectively.

forest species (Smith and Lindenmayer 1988). Therefore, following a brief period where canopy recovery may occur, stands burned at moderate severity may continue to provide vital resources that facilitate faunal persistence (Smucker et al. 2005).

\section{Management implications}

Our study demonstrates that landscape managers can use predictive fire models constructed from digital elevation models, vegetation community distribution, and fire history maps to reliably identify fire refuges. The relatively limited distribution of these refuges increases the need for management actions to ensure their protection (Leonard et al. 2014).

To ensure the ecological processes relevant to their establishment and subsequent use by fauna are maintained, fire managers need to plan for the spatial outcomes of large fires. Our variogram analyses indicate that under extreme fire conditions the occurrence of low-severity fire was spatially dependent on the fire severity in the surrounding landscape (up to $1 \mathrm{~km}$; Table 2). Intense land uses, such as logging, can increase fire severity in different forest types (Thompson et al. 2007, Krawchuk and Cumming 2009). Recently logged forests burned at higher severity than older forest stands (Taylor et al. 2014a). Additionally, clear-fell and salvage-logging practices reduce the quality and extent of habitat across large areas and have the potential to fragment populations (Hutto and Gallo 2006, Lindenmayer et al. 2009a). Therefore, we recommend that logging activities should be relocated from areas within a buffer distance from potential fire refuges. The size of these buffers should be based upon the known ranges and dispersal habits of the old- 

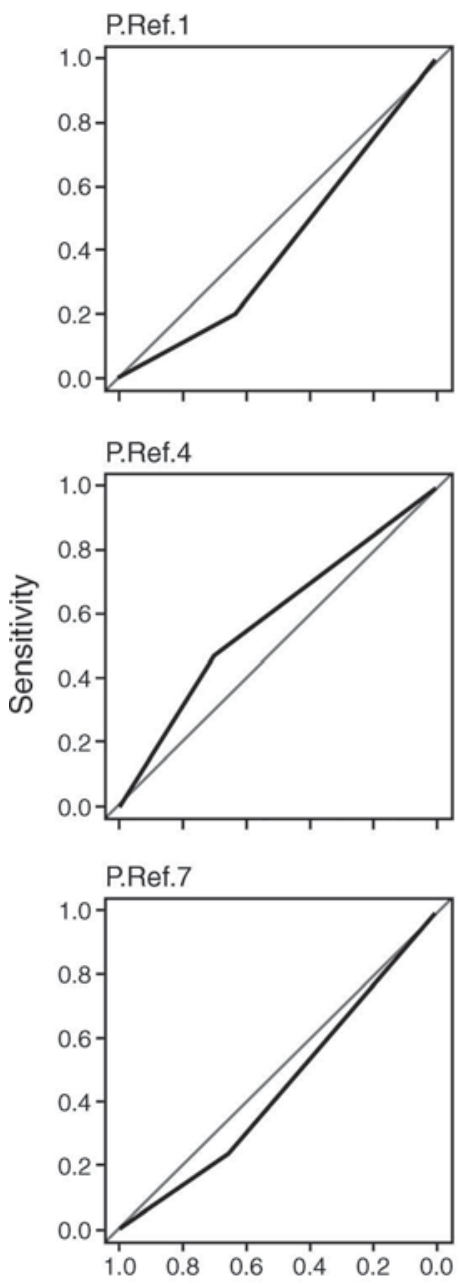

\section{Low-severity fire}

P.Ref.2

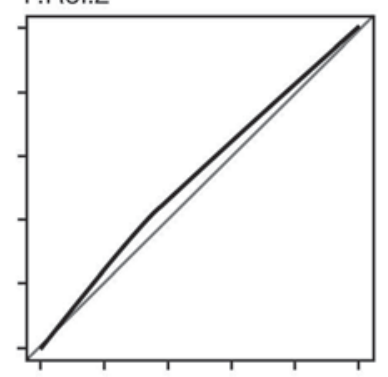

P.Ref.5

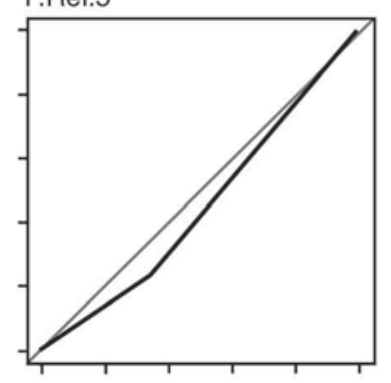

P.Ref.8

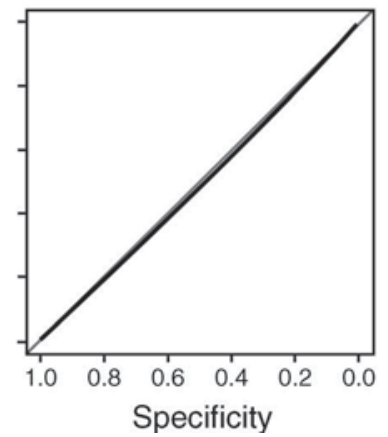

P.Ref.3

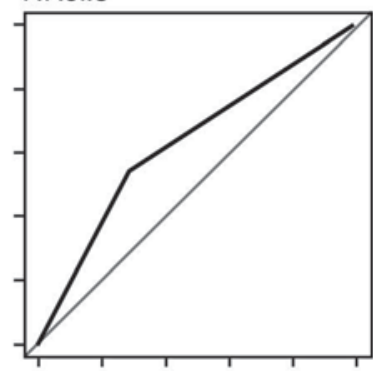

P.Ref.6

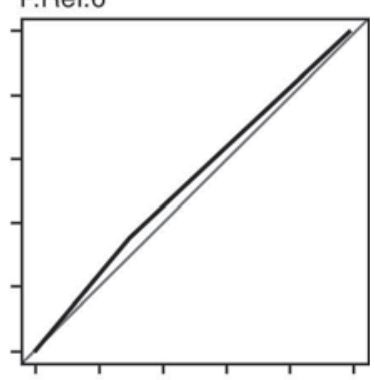

P.Ref.9

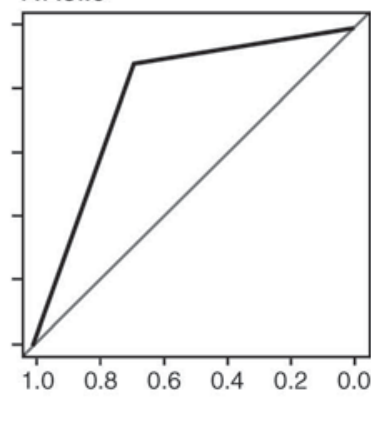

FIG. 6. ROC curves and AUC analysis displaying low-severity fire classification accuracy for each refuge probability class in the O'Shannassy catchment. Sensitivity represents the true positive rate. The gray line indicates a random response and the black line the performance of each refuge class in accurately predicting crown fire.

growth dependent fauna that may use fire refuges (Lindenmayer and Possingham 1996, Pope et al. 2004). Practices which encourage habitat connectivity within these disturbed landscapes may have positive biodiversity outcomes (Gibbons and Lindenmayer 1996, Lindenmayer et al. 2000, 2006).

\section{Conclusions}

Following large-scale wildfires in montane forests, areas of the landscape persist and may act as fire refuges. These areas are ecologically significant, as they can facilitate the presence of old-growth dependent species within extensively burned landscapes (Whelan 1995, Mackey et al. 2002, Robinson et al. 2013). Following crown fires under extreme conditions, fire refuges will only occur in the most sheltered parts of the landscape. To maintain the processes leading to the establishment and subsequent use of fire refuges, it is essential that land management practices that may escalate fire risk and reduce species' use of refuges, such as logging, are excluded from potential refuge areas. Our findings demonstrate that land management agencies can employ predictive landscape models as decision-making tools to map the distribution of fire refuge envelopes enabling their prioritization as areas of significant conservation value.

\section{ACKNOWLEDGMENTS}

We thank Natasha Robinson and one anonymous reviewer for thoughtful comments that improved the manuscript. We thank Amelia Berry for preparing our figures for publication. L. Berry was supported by an Australian Research Council Discovery grant scholarship. Funding for the project was provided by the Fenner School of Environment and Society. 


\section{Literature Cited}

Banks, S. C., M. Dujardin, L. McBurney, D. Blair, M. Barker, and D. B. Lindenmayer. 2011a. Starting points for small mammal population recovery after wildfire: recolonisation or residual populations? Oikos 120:26-37.

Banks, S. C., E. J. Knight, L. McBurney, D. Blair, and D. B. Lindenmayer. 2011 b. The effects of wildfire on mortality and resources for an arboreal marsupial: resilience to fire events but susceptibility to fire regime change. PLoS ONE 6:e22952.

Bessie, W., and E. Johnson. 1995. The relative importance of fuels and weather on fire behavior in subalpine forests. Ecology 76:747-762.

Bowman, D., et al. 2009. Fire in the earth system. Science 324:481-484

Bradstock, R. A., M. Bedward, A. M. Gill, and J. S. Cohn. 2005. Which mosaic? A landscape ecological approach for evaluating interactions between fire regimes, habitat and animals. Wildlife Research 32:409-423.

Bradstock, R. A., K. A. Hammill, L. Collins, and O. Price. 2010. Effects of weather, fuel and terrain on fire severity in topographically diverse landscapes of south-eastern Australia. Landscape Ecology 25:607-619.

Brown, S. M., K. A. Harrisson, R. H. Clarke, A. F. Bennett, and P. Sunnucks. 2013. Limited population structure, genetic drift and bottlenecks characterise an endangered bird species in a dynamic, fire-prone ecosystem. PLoS ONE 8:e59732.

Burton, P. J., M. Parisien, J. A. Hicke, R. J. Hall, and J. T. Freeburn. 2008. Large fires as agents of ecological diversity in the North American boreal forest. International Journal of Wildland Fire 17:754-767

Camp, A., C. Oliver, P. Hessburg, and R. Everett. 1997. Predicting late-successional fire refugia pre-dating European settlement in the Wenatchee Mountains. Forest Ecology and Management 95:63-77.

Castro, J., G. Moreno-Rueda, and J. A. Hodar. 2010. Experimental test of postfire management in pine forests: impact of salvage logging versus partial cutting and nonintervention on bird-species assemblages. Conservation Biology 24:810-819.

Chafer, C. J., M. Noonan, and E. Macnaught. 2004. The postfire measurement of fire severity and intensity in the Christmas 2001 Sydney wildfires. International Journal of Wildland Fire 13:227-240.

Clarke, M. F. 2008. Catering for the needs of fauna in fire management: science or just wishful thinking? Wildlife Research 35:385-394

Cocke, A. E., P. Z. Fulé, and J. E. Crouse. 2005. Comparison of burn severity assessments using differenced normalized burn ratio and ground data. International Journal of Wildland Fire 14:189-198.

Cook, W. M., and R. D. Holt. 2006. Fire frequency and mosaic burning effects on a tallgrass prairie ground beetle assemblage. Biodiversity and Conservation 15:2301-2323.

Driscoll, D. A., et al. 2010. Fire management for biodiversity conservation: key research questions and our capacity to answer them. Biological Conservation 143:1928-1939.

DSE [Department of Sustainability and Environment]. 2009 Remote sensing guideline for assessing landscape-scale fire severity in Victoria's forest estate. Unpublished Technical Manual. Department of Sustainability and Environment, Melbourne, Australia.

DSE [Department of Sustainability and Environment]. 2012. Code of practice for bushfire management on public land. Victorian Government Department of Sustainability and Environment, Melbourne, Australia.

Engel, C. B., T. P. Lane, M. J. Reeder, and M. Rezny. 2013. The meteorology of Black Saturday. Quarterly Journal of the Royal Meteorological Society 139:585-599.

Fawcett, T. 2006. An introduction to ROC analysis. Pattern Recognition Letters 27:861-874.
Franklin, J. F., D. Lindenmayer, J. A. MacMahon, A. McKee, J. Magnuson, D. A. Perry, R. Waide, and D. Foster. 2000 Threads of continuity. Conservation in Practice 1:8-17.

Gibbons, P., and D. Lindenmayer. 1996. Issues associated with the retention of hollow-bearing trees within eucalypt forests managed for wood production. Forest Ecology and Management 83:245-279.

Gill, A., K. Christian, P. Moore, and R. Forrester. 1987. Bushfire incidence, fire hazard and fuel reduction burning. Australian Journal of Ecology 12:299-306.

Haining, R. P. 2003. Spatial data analysis: theory and practice. Cambridge University Press, Cambridge, UK

Hutto, R. L., and S. M. Gallo. 2006. The effects of postfire salvage logging on cavity-nesting birds. Condor 108:817-831.

Johnson, E. A., and S. L. Gutsell. 1994. Fire frequency models, methods and interpretations. Advances in Ecological Research 25:239-287.

Krawchuk, M. A., and S. G. Cumming. 2009. Disturbance history affects lightning fire initiation in the mixedwood boreal forest: observations and simulations. Forest Ecology and Management 257:1613-1622.

Leonard, S. W., A. F. Bennett, and M. F. Clarke. 2014 Determinants of the occurrence of unburnt forest patches: potential biotic refuges within a large, intense wildfire in south-eastern Australia. Forest Ecology and Management 314:85-93.

Lindenmayer, D. 1994. Wildlife corridors and the mitigation of logging impacts on fauna in wood-production forests in south-eastern Australia: a review. Wildlife Research 21:323340.

Lindenmayer, D., D. Blair, L. McBurney, and S. Banks. 2010. Forest phoenix: how a great forest recovers after wildfire. CSIRO, Melbourne, Australia.

Lindenmayer, D., J. Franklin, and J. Fischer. 2006. General management principles and a checklist of strategies to guide forest biodiversity conservation. Biological Conservation 131:433-445.

Lindenmayer, D., B. Mackey, I. Mullen, M. McCarthy, A. Gill, R. Cunningham, and C. Donnelly. 1999. Factors affecting stand structure in forests: are there climatic and topographic determinants? Forest Ecology and Management 123:55-63.

Lindenmayer, D., and M. A. McCarthy. 2002. Congruence between natural and human forest disturbance: a case study from Australian montane ash forests. Forest Ecology and Management 155:319-335.

Lindenmayer, D., and H. Possingham. 1996. Modelling the inter-relationships between habitat patchiness, dispersa capability and metapopulation persistence of the endangered species, Leadbeater's possum, in south-eastern Australia. Landscape Ecology 11:79-105.

Lindenmayer, D. B., W. Blanchard, L. McBurney, D. Blair, S. C. Banks, D. Driscoll, A. L. Smith, and A. M. Gill. 2013. Fire severity and landscape context effects on arboreal marsupials. Biological Conservation 167:137-148.

Lindenmayer, D. B., W. Blanchard, L. McBurney, D. Blair, S. C. Banks, D. A. Driscoll, A. L. Smith, and A. M. Gill. 2014a. Complex responses of birds to landscape-level fire extent, fire severity and environmental drivers. Diversity and Distributions 20:467-477.

Lindenmayer, D. B., R. J. Hobbs, G. E. Likens, C. J. Krebs, and S. C. Banks. 2011. Newly discovered landscape traps produce regime shifts in wet forests. Proceedings of the National Academy of Sciences USA 108:15887-15891.

Lindenmayer, D. B., M. L. Hunter, P. J. Burton, and P. Gibbons. 2009a. Effects of logging on fire regimes in moist forests. Conservation Letters 2:271-277.

Lindenmayer, D. B., W. F. Laurance, and J. F. Franklin. $2012 b$. Global decline in large old trees. Science 338:1305 1306.

Lindenmayer, D. B., W. F. Laurance, J. F. Franklin, G. E. Likens, S. C. Banks, W. Blanchard, P. Gibbons, K. Ikin, D. 
Blair, and L. McBurney. 2014b. New policies for old trees: averting a global crisis in a keystone ecological structure. Conservation Letters 7:61-69.

Lindenmayer, D. B., C. R. Margules, and D. B. Botkin. 2000. Indicators of biodiversity for ecologically sustainable forest management. Conservation Biology 14:941-950.

Lindenmayer, D. B., J. T. Wood, D. Michael, M. Crane, C. MacGregor, R. Montague-Drake, and L. McBurney. 2009 b. Are gullies best for biodiversity? An empirical examination of Australian wet forest types. Forest Ecology and Management 258:169-177.

Lobo, J. M., A. Jiménez-Valverde, and R. Real. 2008. AUC: a misleading measure of the performance of predictive distribution models. Global Ecology and Biogeography 17:145-151.

Mackey, B., S. Berry, S. Hugh, S. Ferrier, T. D. Harwood, and K. J. Williams. 2012. Ecosystem greenspots: identifying potential drought, fire, and climate-change micro-refuges. Ecological Applications 22:1852-1864.

Mackey, B., D. Lindenmayer, M. Gill, M. McCarthy, and J. Lindesay. 2002. Wildlife, fire and future climate: a forest ecosystem analysis. CSIRO Publishing, Collingwood, Victoria, Australia.

McKenzie, D., Z. E. Gedalof, D. L. Peterson, and P. Mote. 2004. Climatic change, wildfire, and conservation. Conservation Biology 18:890-902.

Noble, I., A. Gill, and G. Bary. 1980. McArthur's fire-danger meters expressed as equations. Australian Journal of Ecology 5:201-203.

Nugent, D. T., S. W. Leonard, and M. F. Clarke. 2014. Interactions between the superb lyrebird (Menura novaehollandiae) and fire in south-eastern Australia. Wildlife Research 41:203-211.

Pope, M. L., D. B. Lindenmayer, and R. B. Cunningham. 2004. Patch use by the greater glider (Petauroides volans) in a fragmented forest ecosystem. I. Home range size and movements. Wildlife Research 31:559-568.

Price, O. F., and R. A. Bradstock. 2012. The efficacy of fuel treatment in mitigating property loss during wildfires: insights from analysis of the severity of the catastrophic fires in 2009 in Victoria, Australia. Journal of Environmental Management 113:146-157.

R Development Core Team. 2012. R: a language and environment for statistical computing. R Foundation for Statistical Computing, Vienna, Austria. www.r-project.org

Robinson, N. M., S. W. J. Leonard, A. F. Bennett, and M. F. Clarke. 2014. Refuges for birds in fire-prone landscapes: the influence of fire severity and fire history on the distribution of forest birds. Forest Ecology and Management 318:110-121.

Robinson, N. M., S. W. J. Leonard, E. G. Ritchie, M. Bassett, E. K. Chia, S. Buckingham, H. Gibb, A. F. Bennett, and M. F. Clarke. 2013. Review: refuges for fauna in fire-prone landscapes: their ecological function and importance. Journal of Applied Ecology 50:1321-1329.
Roy, D. P., L. Boschetti, and S. N. Trigg. 2006. Remote sensing of fire severity: assessing the performance of the normalized burn ratio. Geoscience and Remote Sensing Letters, IEEE $3: 112-116$.

Sharples, J. J., R. H. McRae, and S. R. Wilkes. 2012. Windterrain effects on the propagation of wildfires in rugged terrain: fire channelling. International Journal of Wildland Fire 21:282-296

Sing, T., O. Sander, N. Beerenwinkel, and T. Lengauer. 2005. ROCR: visualizing classifier performance in R. Bioinformatics 21:3940-3941.

Smith, A., and D. Lindenmayer. 1988. Tree hollow requirements of Leadbeater's possum and other possums and gliders in timber production ash forests of the Victorian Central Highlands. Wildlife Research 15:347-362.

Smucker, K. M., R. L. Hutto, and B. M. Steele. 2005. Changes in bird abundance after wildfire: importance of fire severity and time since fire. Ecological Applications 15:1535-1549.

Stuart-Smith, K., I. T. Adams, and K. W. Larsen. 2002. Songbird communities in a pyrogenic habitat mosaic International Journal of Wildland Fire 11:75-84.

Taylor, A. H., and C. N. Skinner. 1998. Fire history and landscape dynamics in a late-successional reserve, Klamath Mountains, California, USA. Forest Ecology and Management 111:285-301.

Taylor, C., M. A. McCarthy, and D. B. Lindenmayer. 2014a. Non-linear effects of stand age on fire severity. Conservation Letters 7(4):355-370.

Taylor, D., M. Tharapos, and S. Sidaway. 2014b. Downward accountability for a natural disaster recovery effort: evidence and issues from Australia's Black Saturday. Critical Perspectives on Accounting 25(7):633-651.

Teague, B., R. McLeod, and S. Pascoe. 2010. Final report, 2009 Victorian bushfires royal commission. Parliament of Victoria, Melbourne, Victoria, Australia.

Thompson, J. R., T. A. Spies, and L. M. Ganio. 2007. Reburn severity in managed and unmanaged vegetation in a large wildfire. Proceedings of the National Academy of Sciences USA 104:10743-10748.

Tolhurst, K., W. Street, and V. Creswick. 2010. Report on fire danger ratings and public warning. Victorian Bushfires Roya Commission, Melbourne, Victoria, Australia.

Turner, M. G., and W. H. Romme. 1994. Landscape dynamics in crown fire ecosystems. Landscape Ecology 9(1):59-77.

Whelan, R. J. 1995. The ecology of fire. Cambridge University Press, Cambridge, UK.

Wood, S. W., B. P. Murphy, and D. M. J. S. Bowman. 2011. Firescape ecology: how topography determines the contrasting distribution of fire and rain forest in the south-west of the Tasmanian Wilderness World Heritage Area. Journal of Biogeography 38:1807-1820.

Worster, A., J. Fan, and S. Upadhye. 2006. Understanding receiver operating characteristic (ROC) curves. Canadian Journal of Emergency Medicine 8:19-20.

\section{Supplemental Material}

Ecological Archives

Appendices A-D are available online: http://dx.doi.org/10.1890/14-1699.1.sm

Data Availability

Data associated with this paper have been deposited in LTERN: http://www.ltern.org.au/knb/metacat/ltern2.288.46/html 